WHOI $-78-12$

WIND STRESS ON THE OCEAN OVER THE

EASTERN CONTINENTAL SHELF OF NORTH AMERICA

by

Peter M. Saunders

WOODS HOLE OCEANOGRAPHIC INSTITUTION

Woods Hole, Massachusetts 02543

July 1978

TECHNICAL REPORT

Prepared for the Office of Naval Research under Contract N00014-74-C-0262; NR 083-004.

Reproduction in whole or in part is permitted

for any purpose of the United States Government.

In citing this report in a bibliography, the

reference should be given to the "Journal of

Physical Oceanography, Vol. 7, No. 4, July 1977, pp. 555-566".

Approved for public release; distribution unIimited.

Approved for Distribution: Valentine Worthington, Chairman Department of Physical Oceanography 

Reprinted from Journal of Physical Oceanography, Vol. 7, No. 4, July 1977
American Meteorological Society
Printed in U. S. A.

\title{
Wind Stress on the Ocean over the Eastern Continental Shelf of North America ${ }^{1}$
}

\author{
Peter M. SAunders ${ }^{2}$ \\ Woods Hole Oceanographic Institution, Woods Hole, Mass. 02543
}

(Manuscript received 8 December 1976, in revised form 2 March 1977)

\section{ABSTRACT}

Employing one million ship reports gathered in the years 1941-72 seasonal averages of the wind stress and its standard deviation have been computed for the shelf region of the eastern North American continent (out to a depth of $200 \mathrm{~m}$ ). A drag coefficient is assumed which increases with wind speed, from $1.0 \times 10^{-3}$ at $5 \mathrm{~m} \mathrm{~s}^{-1}$ to $2.3 \times 10^{-3}$ at $25 \mathrm{~m} \mathrm{~s}^{-1}$. Atmospheric stratification is taken into account but its effect is shown to be small.

In the summer season the 32-year climatological wind stress is toward the northeast, having a magnitude close to $0.25 \mathrm{dyn} \mathrm{cm}^{-2}$ throughout the entire shelf region. In the three other seasons the stress is directed toward the south and east being strongest in winter $\left(1-1.5 \mathrm{dyn} \mathrm{cm}^{-2}\right)$ and weakest in fall $\left(0.25-0.5 \mathrm{dyn}^{-2}\right)$. In addition to the expected increase in magnitude with increasing latitude remarkable small-scale variability occurs. An offshore increase in stress is widespread and dominates the midAtlantic Bight; in winter the stress there increases from 0.5 to $1.0 \mathrm{dyn} \mathrm{cm}^{-2}$ in going $200 \mathrm{~km}$ offshore. In the Gulf of Maine and especially in the Gulf of St. Lawrence local maxima occur; the tail of the Grand Banks $500 \mathrm{~km}$ from shore shows a minimum. Probably much of this variation is associated with the intensity (and frequency) of cyclonic activity rather than directly with changes in friction at the underlying surface. Some oceanographic consequences are commented on but the computations are principally intended as a data source for further research.

\section{Introduction}

Dynamical studies of the circulation in shallow coastal regions require knowledge of atmospheric forcing, including pressure, wind stress and heat fluxes. In this paper I have made use of the archived data incorporated in the voluntary surface meteorological messages reported at standard times (0000 and 1200 GMT) by commercial shipping. Such data, made at random positions, seemed most suited for calculations of the climatology of atmospheric forcing and the wind stress was chosen because it is a significant term. It is not clear to the author what properties of the wind stress are most important so that the simplest statistics, namely, mean and standard deviation, have been chosen. However, to provide further data polar histograms of stress frequency have also been computed. It was my aim to condense the million ship data to a somewhat more manageable size: thus this report should be regarded as the description of a data source or a data summary rather than the results of a scientific investigation.

\footnotetext{
${ }^{1}$ Contribution No. 3880 from the Woods Hole Oceanographic Institution.

${ }^{2}$ Present affiliation: Institute of Oceanographic Sciences, Wormley, Godalming, Surrey, GU8 5UB, England.
}

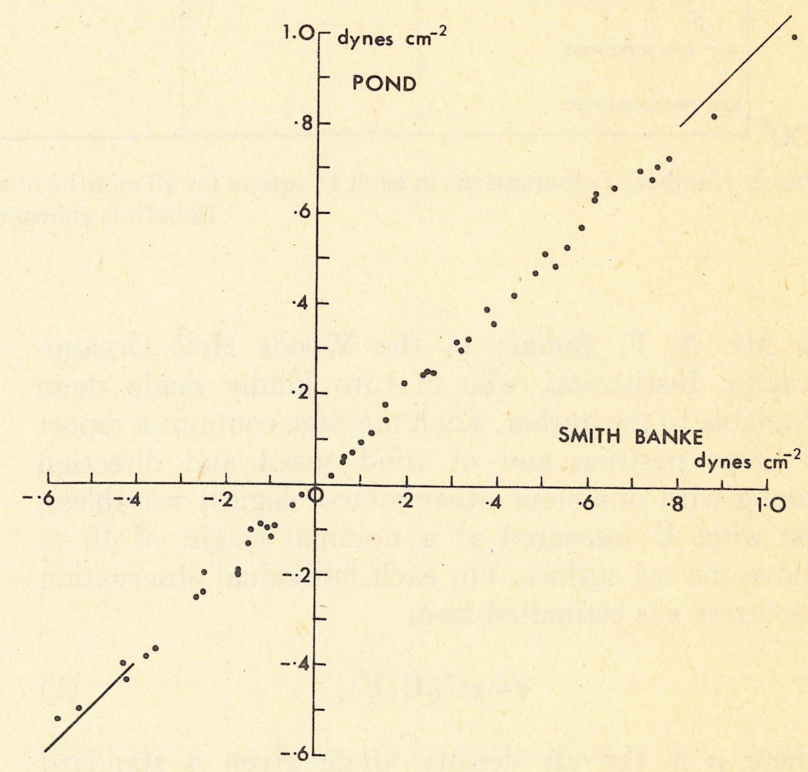

FIG. 1. A comparison of three-month stress averages (both east and north) computed employing two drag coefficients (see text) for $1^{\circ}$ squares in the area $70-80^{\circ} \mathrm{W}, 40-50^{\circ} \mathrm{N}$. Solid line has a slope of unity.

\section{Choice of drag coefficient}

The National Climatic Center at Asheville, N.C., furnished magnetic tapes of surface marine messages 


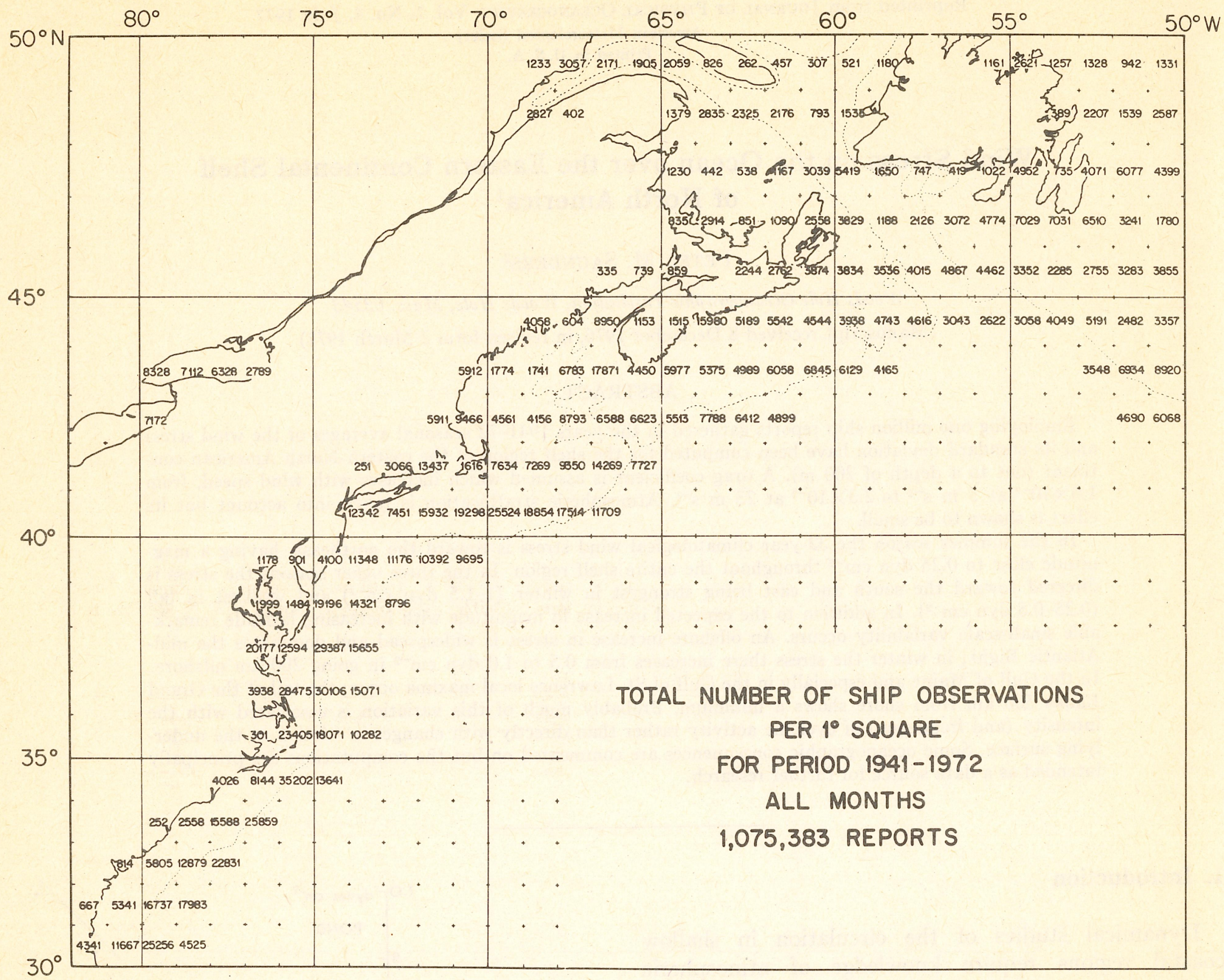

FIG. 2. Number of observations in each $1^{\circ}$ square for all months of the period 1941-72 for the region studied in this paper. The $200 \mathrm{~m}$ isobath is shown as a dotted line.

to Mr. A. F. Bunker of the Woods Hole Oceanographic Institution, who in turn kindly made them available to the author. Each message contains a report of ships position and of wind speed and direction (along with numerous other meteorological variables), the wind $\mathbf{U}$ measured at a nominal height of $10 \mathrm{~m}$ above the sea surface. For each individual observation the stress $\tau$ is estimated from

$$
\tau=\rho C_{D} \mathbf{U}|\mathbf{U}|
$$

where $\rho$ is the air density (here given a standard value of $1.2 \times 10^{-3} \mathrm{~g} \mathrm{~cm}^{-3}$ ) and $C_{D}$ is the drag coefficient. The drag coefficient is itself a function of wind speed, of air-sea temperature difference and possibly of sea state, and is the subject of considerable controversy. The recent findings of Smith and Banke (1975) have been adopted in this paper (see also Saunders, 1976), which under neutral conditions give a value for $C_{D}$ of

$$
C_{D}=0.63 \times 10^{-3}+0.66 \times 10^{-6}|\mathbf{U}|
$$

where $|\mathbf{U}|$ is measured in centimeters per second. This equation yields a value of $10^{3} C_{D}=1.0$ at $5 \mathrm{~m} \mathrm{~s}^{-1}$, 1.3 at $10 \mathrm{~m} \mathrm{~s}^{-1}, 1.6$ at $15 \mathrm{~m} \mathrm{~s}^{-1}$ and 2.3 at $25 \mathrm{~m} \mathrm{~s}^{-1}$.

It is, of course, unsatisfactory to relate a nondimensional parameter $C_{D}$ to the magnitude of a physical variable, viz., $|\mathbf{U}|$, and Eq. (2) is employed here merely for computational convenience. Charnock (1955) has suggested that the roughness length $z_{0}$ is given by

$$
z_{0}=U_{*}^{2} /(a g)
$$

where $U_{*}$ is the friction velocity $\left[=(|\tau| / \rho)^{\frac{1}{2}}\right]$ and $g$ the acceleration of gravity. If the constant $a$ is assigned a value near 80 and the logarithmic profile equation is employed, Smith and Banke (1975) show 

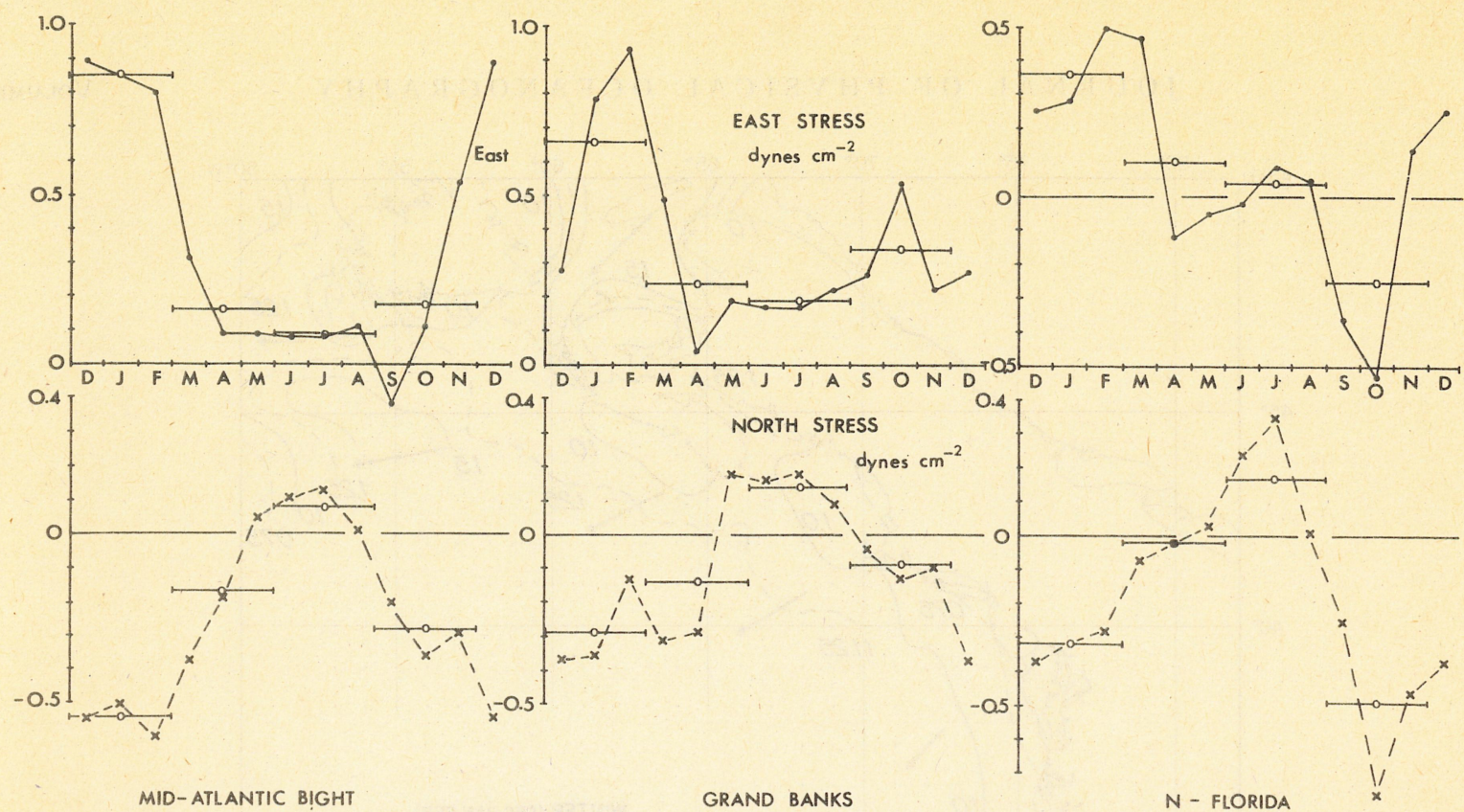

FIG. 3. Monthly averaged east and north stress components in areas of approximately $3^{\circ} \times 1^{\circ}$ for the period $1941-72$. Horizontal bars indicate three-month averages. (a) mid-Atlantic bight $\left(40^{\circ} \mathrm{N}, 70^{\circ} \mathrm{W}\right.$; total number of observations 42681$)$; (b) tail of, Grand Banks $\left(43^{\circ} \mathrm{N}, 50^{\circ} \mathrm{W}\right.$; total number of observations 19402$)$; (c) northern Florida $\left(30^{\circ} \mathrm{N}, 80^{\circ} \mathrm{W}\right.$; total number of observations 17008$)$.

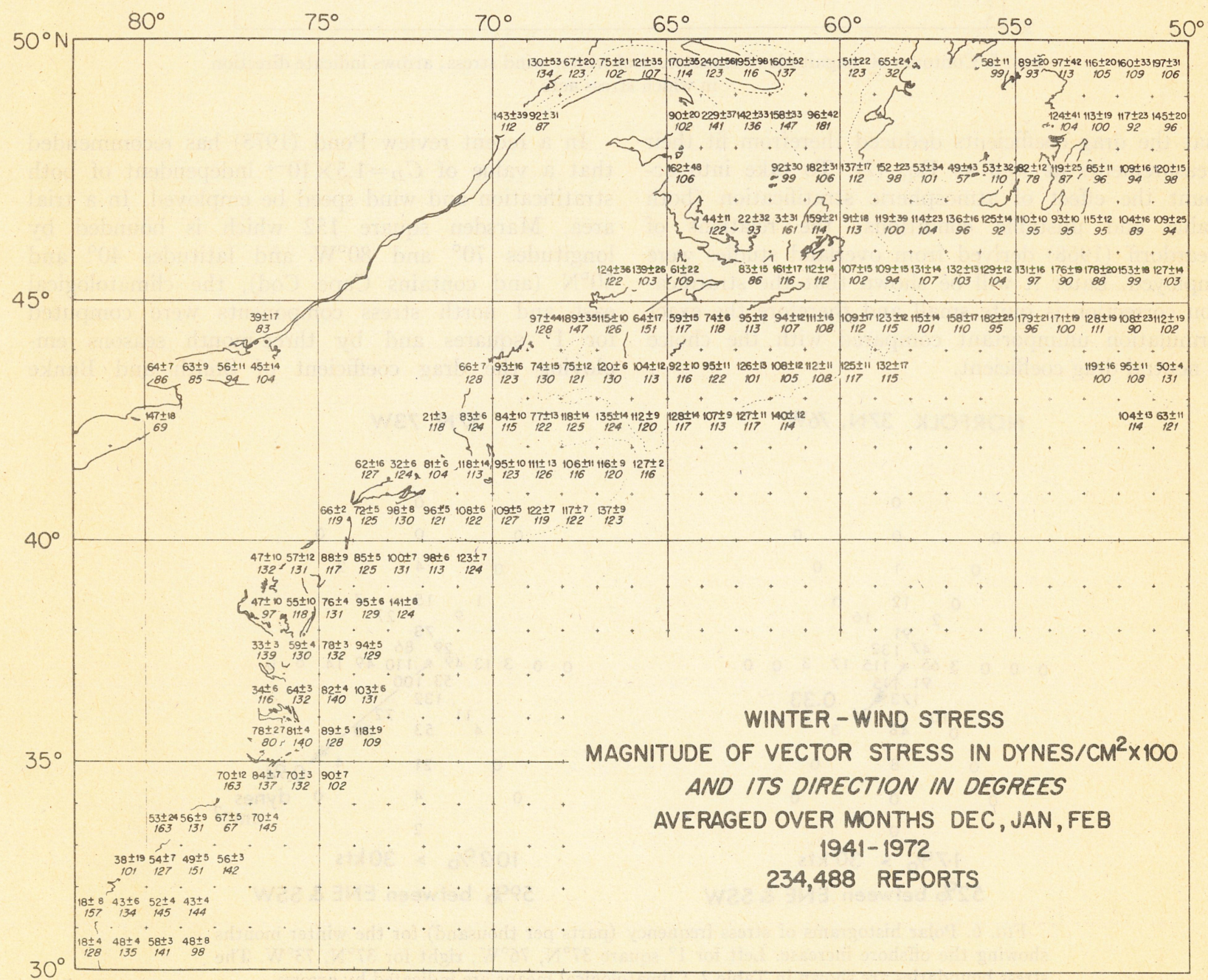

Fig. 4. Magnitude and direction of the climatological winter wind stress. The standard error of the magnitude of the stress is also shown (e.g., \pm 13$)$. 


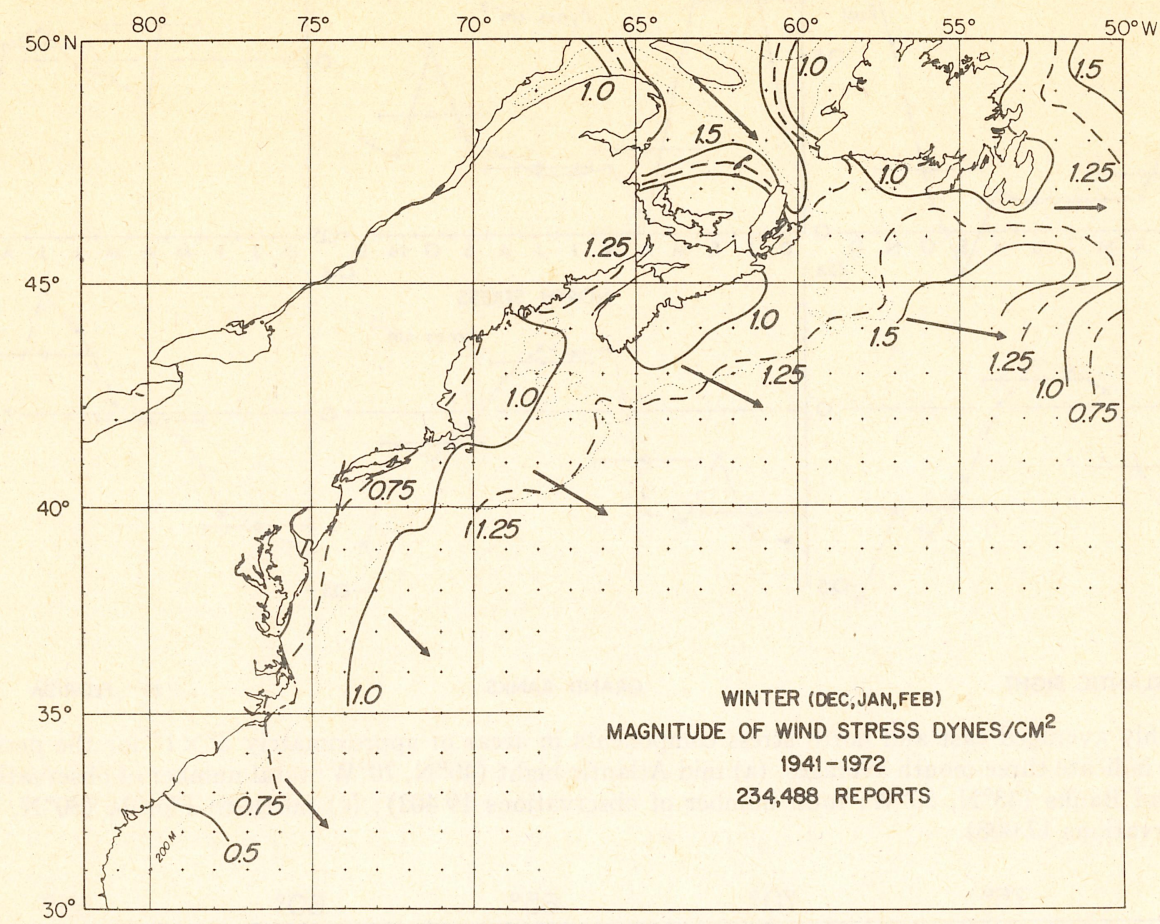

FIG. 5. Contours of magnitude of climatological winter wind stress; arrows indicate direction in which stress acts.

that the drag coefficients deduced therefrom fit their measurements as well as Eq. (2). To take into account the effect of atmospheric stratification (both stable and unstable conditions) the relations of Deardorff (1968) derived from overland studies were employed. Later it will be shown that the stratification correction is quite small and therefore the exact formulation unimportant compared with the choice of neutral drag coefficient.

NORFOLK $37 \mathrm{~N}, 76 \mathrm{~W}$

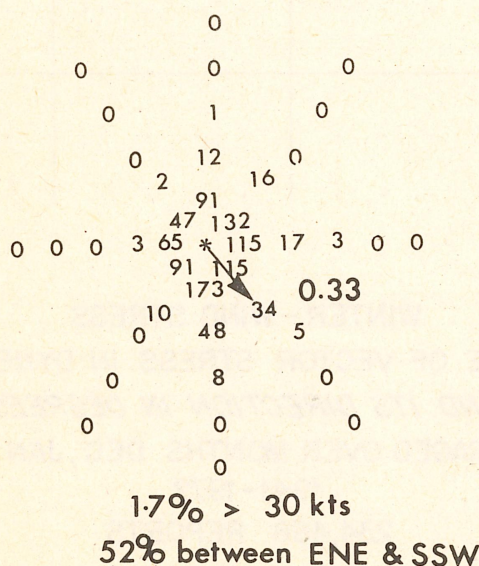

In a recent review Pond (1975) has recommended that a value of $C_{D}=1.5 \times 10^{-3}$ independent of both stratification and wind speed be employed. In a trial area, Marsden square 152 which is bounded by longitudes $70^{\circ}$ and $80^{\circ} \mathrm{W}$ and latitudes $40^{\circ}$ and $50^{\circ} \mathrm{N}$ (and contains Cape Cod), the climatological east and north stress components were computed for $1^{\circ}$ squares and by three-month seasons employing the drag coefficient of Smith and Banke

$37 N, 73 W$

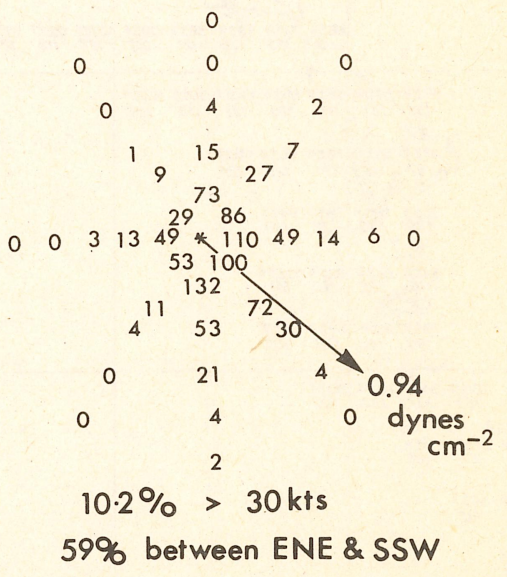

FIG. 6. Polar histograms of stress frequency (parts per thousand) for the winter months showing the offshore increase: Left for $1^{\circ}$ square $37^{\circ} \mathrm{N}, 76^{\circ} \mathrm{W}$; right for $37^{\circ} \mathrm{N}, 73^{\circ} \mathrm{W}$. The stress boundaries are shown in Table 2 . Climatological means are indicated by arrows. 
TABLE 1. Summary of the average standard deviation of a component of the wind stress $\sigma=\frac{1}{2}\left(\sigma_{E}+\sigma_{N}\right)\left[\right.$ dyn $\left.\mathrm{cm}^{-2}\right]$.

\begin{tabular}{|c|c|c|c|c|c|c|c|c|c|c|}
\hline \multirow[b]{2}{*}{ Location } & \multicolumn{2}{|c|}{ Winter } & \multicolumn{2}{|c|}{ Spring } & \multicolumn{2}{|c|}{ Summer } & \multicolumn{2}{|c|}{ Fall } & \multicolumn{2}{|c|}{ Annual } \\
\hline & Inshore & Offshore & Inshore & Offshore & Inshore & Offshore & Inshore & Offshore & Inshore & Offshore \\
\hline South of $42^{\circ} \mathrm{N}$ & 1.5 & 2.5 & 1.0 & 2.0 & 0.5 & 1.0 & 1.0 & 2.0 & 1.0 & 2.0 \\
\hline Gulf of Maine/Nova & 25 & 30 & 15 & 2.5 & 1.0 & 15 & 15 & 0 & 15 & 20 \\
\hline $\begin{array}{l}\text { Scotia } \\
\text { Gulf of St. Lawrence }\end{array}$ & 2.5 & $\begin{array}{l}.0 \\
4.5\end{array}$ & 2.0 & 3.0 & $\begin{array}{l}1.0 \\
1.0\end{array}$ & $\begin{array}{l}1.0 \\
1.0\end{array}$ & 2.0 & $\begin{array}{l}2.0 \\
3.0\end{array}$ & $\begin{array}{l}1.3 \\
2.0\end{array}$ & $\begin{array}{l}2.0 \\
3.0\end{array}$ \\
\hline Newfoundland & 3.0 & 4.0 & 2.0 & 2.5 & 1.0 & 1.5 & 2.0 & 2.5 & 2.0 & 2.5 \\
\hline
\end{tabular}

and that suggested by Pond. As seen in Fig. 1 the results are indistinguishable which can be interpreted to mean that the rms scalar wind speed is close to $13 \mathrm{~m} \mathrm{~s}^{-1}$, the value at which the two drag coefficients are identical. This result covers a range of values of average stress from 0 to $1.0 \mathrm{dyn} \mathrm{cm}^{-2}$; larger average values, which involve more frequent strong winds $\left(>20 \mathrm{~m} \mathrm{~s}^{-1}\right)$ may be expected to yield lower values of average stress for $C_{D}=1.5 \times 10^{-3}$ than those obtained with Eq. (2)-perhaps $30 \%$ less with climatological values from Eq. (2) of 2.0 dyn $\mathrm{cm}^{-2}$.

Although all the results reported in this paper have included the effect of atmospheric stratification, trial computations have been made assuming neutral conditions; the principal difference is a reduction in computer running time by a factor of nearly one-half! The differences in average stress are characteristically $0.02-0.05$ dyn $\mathrm{cm}^{-2}$ in winter (larger with stratification taken into account) and $0.01-0.03 \mathrm{dyn} \mathrm{cm}^{-2}$ in summer (smaller with stratification taken into account). These comparisons were made for Marsden square 150 which is bounded by longitudes $50^{\circ}$ and $60^{\circ} \mathrm{W}$ and latitudes $40^{\circ}$ and $50^{\circ} \mathrm{N}$ (and contains Newfoundland).

\section{Spatial or temporal resolution?}

The total number of observations for the period under study (1941-72) in the area between the coast and the $200 \mathrm{~m}$ isobath, which was taken as the limit of the continental shelf, is approximately one million. The number in each of the approximately $2001^{\circ}$ squares shown in Fig. 2 is thus characteristically a few thousand, ranging from approximately 500-30000. The question to be answered is to what extent can the annual variation in the climatological stress be represented on a small scale: are the data dense enough to permit a description of both? Because of the magnitude of the stress associated with the passage of weather systems the standard deviation $\sigma$ of the stress in a period of the order of a month or longer is 1-5 dyn $\mathrm{cm}^{-2}$. If there are $N$ observations in this period, the standard error $\epsilon$ in the estimate of the mean is $\sigma / N^{\frac{1}{2}}$ (assuming a Gaussian process). If $\sigma=3$ dyn $\mathrm{cm}^{-2}$ and $N=100, \epsilon=0.3 \mathrm{dyn} \mathrm{cm}^{-2}$, whereas if $N=1000, \epsilon=0.1$ dyn $\mathrm{cm}^{-2}$. The latter clearly is a better target for either a seasonal description or a discussion of the spatial variation. It will be seen by examining Fig. 2 that almost all $1^{\circ}$ squares contain less than 12000 data values which would then be the minimum required for a monthly description of the average stress. Hence we must either group the squares (approximately by 3 ) or group the months (also by 3 ). The latter choice has been made here, computing the seasonal climatology by $1^{\circ}$ squares so as to maximize spatial resolution.
HALIFAX $44 \mathrm{~N}, 63 \mathrm{~W}$

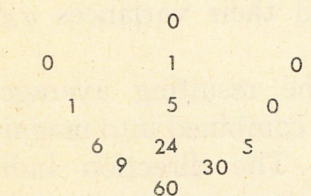

$\begin{array}{llllllll}311 & 21 & 49^{60} & 48 \\ 141 & 8042 \quad 7 \quad 1\end{array}$

3895

$7^{16}{ }_{41}^{118}{ }_{18}^{55}=0.74$

$\begin{array}{lll}2 & 17 & 1\end{array}$

$0 \quad 3 \quad 0$

0

$13.1 \%>30 \mathrm{kts}$

$52 \%$ between NNE \& SSE
$44 N, 55 W$

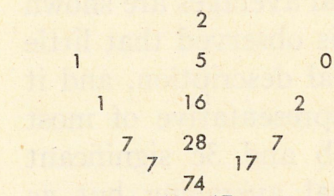

$\begin{array}{llllllllll} & 0 & 11 & 8 & 53^{74} * 47 & 47 & 96 & 70 & 26 & 14\end{array}$

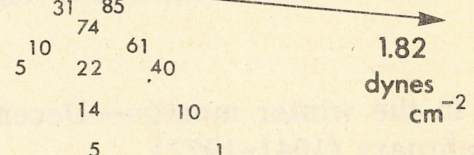

FIG. 7. As in Fig. 6 but for $44^{\circ} \mathrm{N}, 63^{\circ} \mathrm{W}$ (left) and $44^{\circ} \mathrm{N}, 55^{\circ} \mathrm{W}$ (right). 


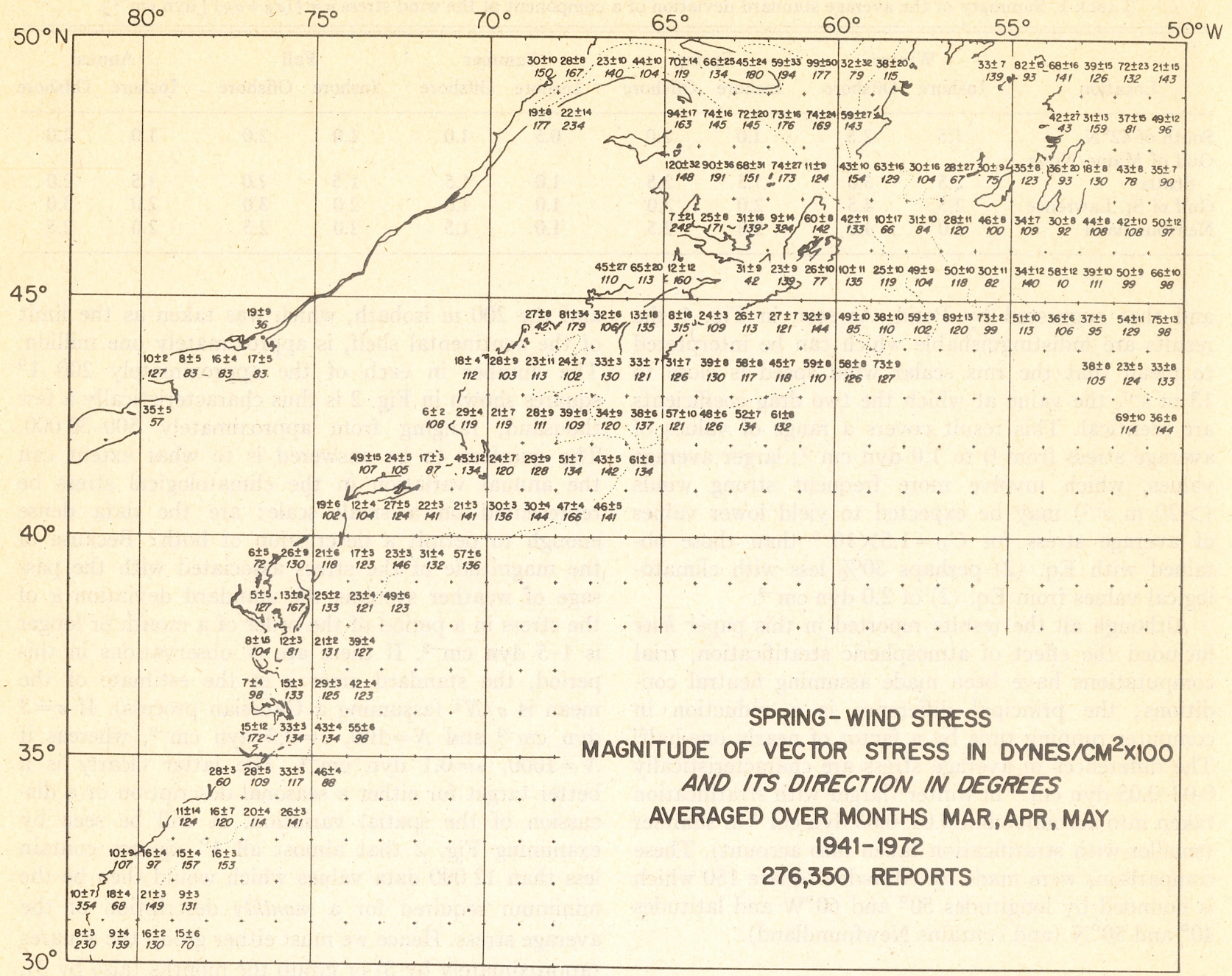

FIG. 8. Magnitude (and standard error) and direction of the climatological spring wind stress.

To illustrate the seasonal variation by months the average stress components have been computed for three small regions $\left(1^{\circ} \times 3^{\circ}\right)$ in the center, at the northeastern margin, and at the southern margin of the area under study; these are shown in Figs. 3a-3c, respectively. The 3 month seasonal averages are shown as horizontal bars. In Fig. 3a it is observed that little information is lost by the seasonal description, and it is believed that this result is representative of most of the area studied. In Figs. $3 \mathrm{~b}$ and $3 \mathrm{c}$ significant peaks are diminished by seasonal averaging but as will be seen later both of these areas exhibit regional peculiarities.

\section{Wind stress in the winter months-December, January, February (1941-1972)}

Given a wind observation in one of the above months of the 32-year period an instantaneous stress $\tau$ is computed from Eqs. (1) and (2) and those formulated by Deardoff (1968) to take account of atmo- spheric stratification, mainly air-sea temperature difference. The stress is resolved into east $\tau_{E}$ and north $\tau_{N}$ components and accumulated by $1^{\circ}$ squares. The number of observations $N$ and squares of stress components are also accumulated so that mean stress components and their variances $\sigma_{E}^{2}$ and $\sigma_{N}{ }^{2}$ can be calculated.

In Fig. 4 the resulting average east and north components are combined into magnitude and direction and tabulated. The direction indicated is that in which the average stress acts, a convention appropriate for oceanographic studies. Values of the standard error of the magnitude of the mean $\epsilon_{r}$ have also been tabulated and the standard error of the direction $\epsilon_{\theta}$ can readily be calculated from the approximate expression $\epsilon_{\tau} /|\bar{\tau}|$. The above quantities are assumed related to the standard error of the east $\epsilon_{E}$ and north $\epsilon_{N}$ component averages by the relations

$$
\begin{aligned}
& \epsilon_{\tau}=\left(\epsilon_{E^{2}}{ }^{2} \bar{\tau}_{E^{2}}+\epsilon_{N}^{2} \bar{\tau}_{N}^{2}\right)^{\frac{1}{2}} /|\bar{\tau}|, \\
& \epsilon_{\theta}=\left(\epsilon_{E^{2}}{ }^{2} \bar{\tau}_{N}{ }^{2}+\epsilon_{N}{ }^{2} \bar{\tau}_{E^{2}}\right)^{\frac{1}{2}} /|\bar{\tau}|^{2},
\end{aligned}
$$




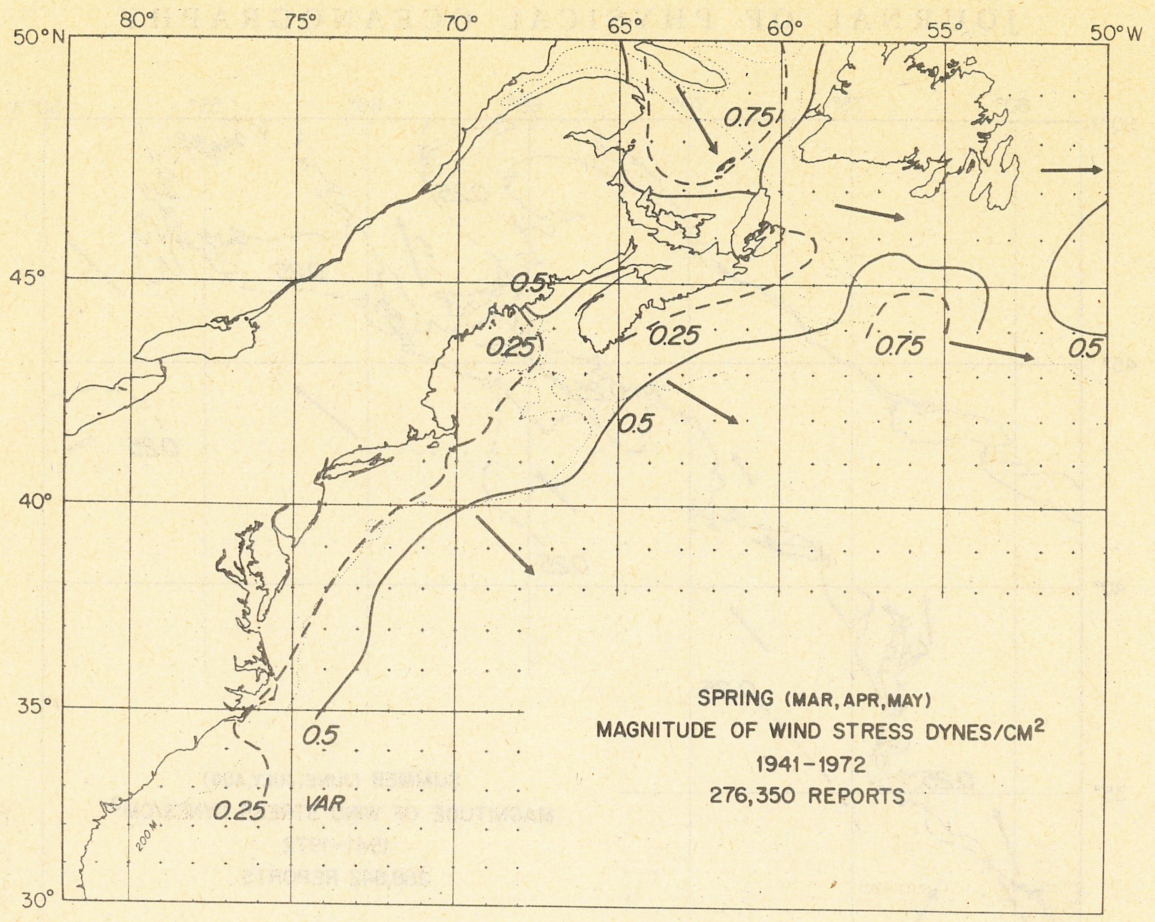

FIG. 9. Contours of magnitude from Fig. 8.

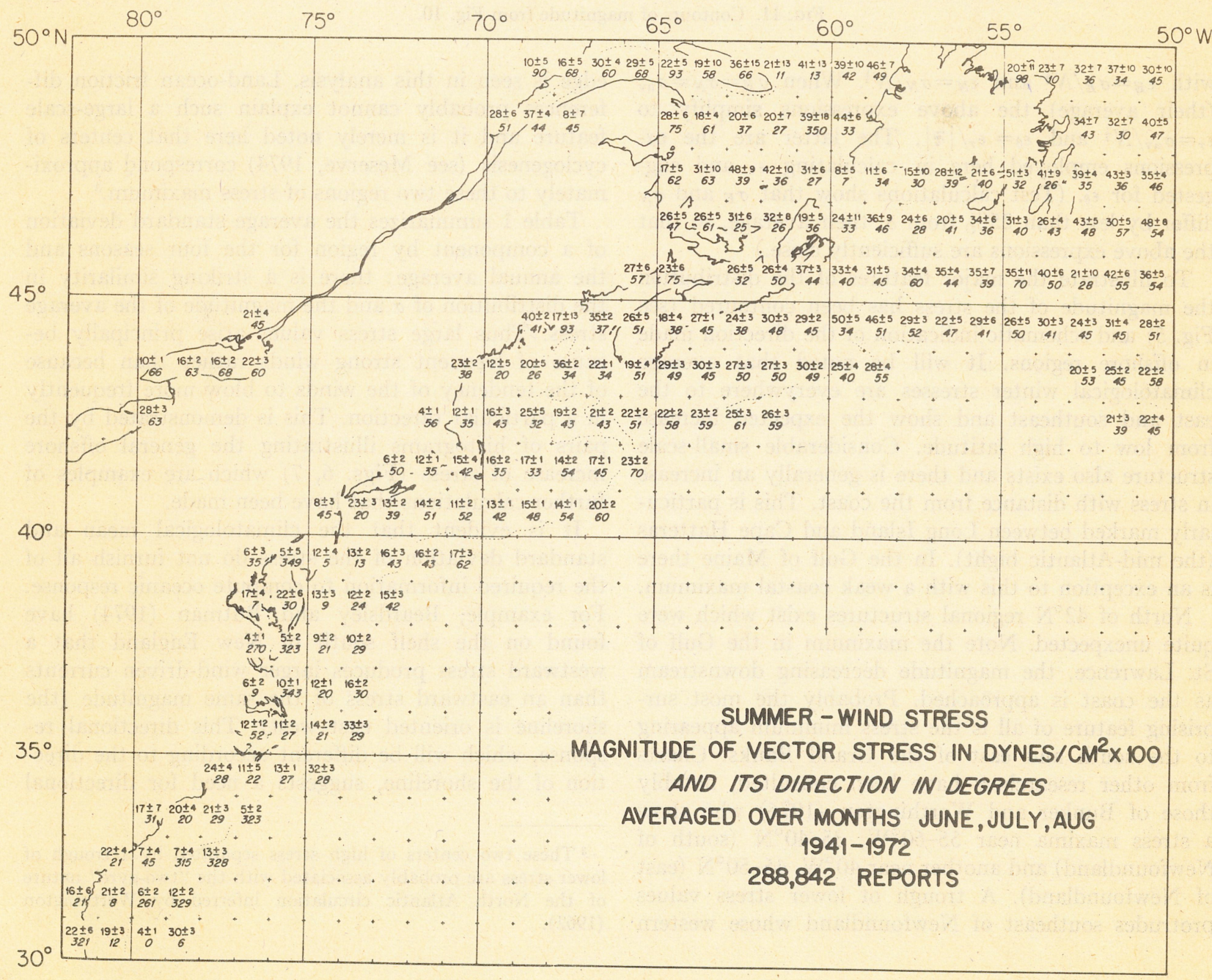

FIG. 10. As in Fig. 8 except for summer. 


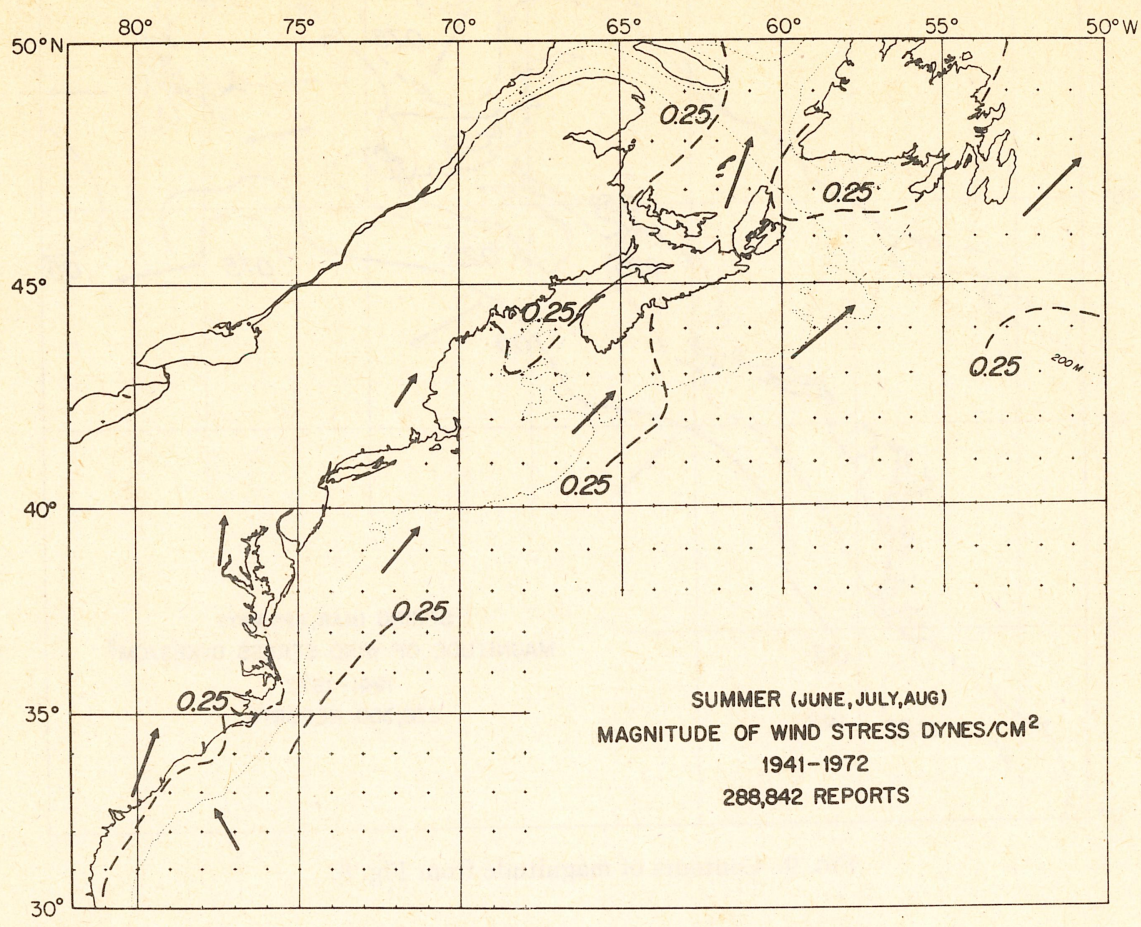

FIG. 11. Contours of magnitude from Fig. 10.

with $\epsilon_{E}=\sigma_{E} / N^{\frac{1}{2}}$ and $\epsilon_{N}=\sigma_{N} / N^{\frac{1}{2}}$. When $\sigma_{E}=\sigma_{N}=\sigma_{\text {av }}$ (their average) the above expressions simplify to $\epsilon_{\tau}=\sigma_{\mathrm{av}} / N^{\frac{1}{2}}$ and $\epsilon_{\theta}=\epsilon_{\tau} /|\overline{\boldsymbol{\tau}}|$. The latter are the expressions employed here in calculating $\epsilon_{\tau}$ and suggested for $\epsilon_{\theta}$. (Test calculations show that $\sigma_{E}$ and $\sigma_{N}$ differ by less than $25 \%$ from $\sigma$, their average, so that the above expressions are sufficiently close.)

To illustrate the major features of the distribution the magnitude of the stress has been contoured (see Fig. 5) and schematic indication of the direction made in offshore regions. It will be noted that average climatological winter stresses are everywhere to the east and southeast and show the expected increase from low to high latitude. Considerable small-scale structure also exists and there is generally an increase in stress with distance from the coast. This is particularly marked between Long Island and Cape Hatteras (the mid-Atlantic bight). In the Gulf of Maine there is an exception to this with a weak coastal maximum.

North of $42^{\circ} \mathrm{N}$ regional structures exist which were quite unexpected. Note the maximum in the Gulf of St. Lawrence, the magnitude decreasing downstream as the coast is approached. Probably the most surprising feature of all is the stress minimum appearing to the south and east of the Grand Banks. Charts from other researchers have been consulted, notably those of Bunker and Worthington (1976) who show a stress maxima near $55-60^{\circ} \mathrm{W}, 35-40^{\circ} \mathrm{N}$ (south of Newfoundland) and another near $40^{\circ} \mathrm{W}, 45-50^{\circ} \mathrm{N}$ (east of Newfoundland). A trough of lower stress values protrudes southeast of Newfoundland whose western edge is seen in this analysis. Land-ocean friction differences probably cannot explain such a large-scale feature and it is merely noted here that centers of cyclogenesis (see Meserve, 1974) correspond approximately to these two regions of stress maximum. ${ }^{3}$

Table 1 summarizes the average standard deviation of a component by region for the four seasons and the annual average: there is a striking similarity in the distribution of $\sigma$ and the magnitude of the average stress. Thus large stress values arise principally because of frequent strong winds rather than because of the tendency of the winds to blow more frequently in a particular direction. This is demonstrated by the pairs of histograms illustrating the general offshore increase of stress (Figs. 6, 7) which are examples of further calculations that have been made.

It is evident that the climatological mean and standard deviation of the stress do not furnish all of the required information to compute oceanic response. For example, Beardsley and Butman (1974) have found on the shelf south of New England that a westward stress produces larger wind-driven currents than an eastward stress of the same magnitude (the shoreline is oriented east-west). This directional response, which will be different according to the direction of the shoreline, suggests a need for directional

\footnotetext{
${ }^{3}$ These two centers of high stress separated by a trough of lower stress are probably associated with the "two-gyre" nature of the North Atlantic circulation inferred by Worthington (1962).
} 
stress data. Accordingly, polar histograms have been constructed for each $1^{\circ}$ square and season for eight principal directions. The stress boundaries chosen, which are described in Table.2, correspond in the case of neutral stratification to $10 \mathrm{kt}$ wind intervals and have average values which are also tabulated. From the frequency distributions the average stress may be deduced by octants, quadrants, etc. These polar histograms (4 seasons $\times 8$ directions $\times 5$ magnitudes $\times 2001^{\circ}$ squares $=32000$ ) represent a reduction by a factor of only 30 on the original data set and cannot be reproduced here.

\section{Wind stress in the spring months-March, April, May (1941-72)}

The results derived for the spring months (Figs. 8, 9) are generally very similar to those obtained in the winter months. Directions of the climatological stress
TABLE 2. Stress boundaries for polar histograms.

\begin{tabular}{lccccc}
\hline \hline Identification & 1 & 2 & 3 & 4 & 5 \\
Stress range $\left(\right.$ dyn cm $\left.\mathrm{cm}^{-2}\right)$ & $<1.5$ & $1.5-4.4$ & $4.4-9.4$ & $9.4-17.0$ & $>17.0$ \\
Mean stress $\left(\mathrm{dyn} \mathrm{cm}^{-2}\right)$ & 1 & 3 & 7 & 13 & $25-30$ \\
Wind range* $(\mathrm{kt})$ & $<20$ & $20-30$ & $30-40$ & $40-50$ & $>50$ \\
\hline
\end{tabular}

* For neutral stratification

are similar to those of Fig. 4 but magnitudes are between one-fourth and one-half of the winter months and correspondingly gradients are weaker. In the region of simple offshore increase, south of $42^{\circ} \mathrm{N}$, the inshore stress, besides being smaller, is more nearly easterly, i.e., it is $20-30^{\circ}$ to the left of the offshore stress. Such an effect might be ascribed to friction, but since it is absent in winter (Figs. 4, 5) it is more likely to result from the temperature contrast between land being warmer than the sea in the spring and colder in the winter. It will be noted that offshore

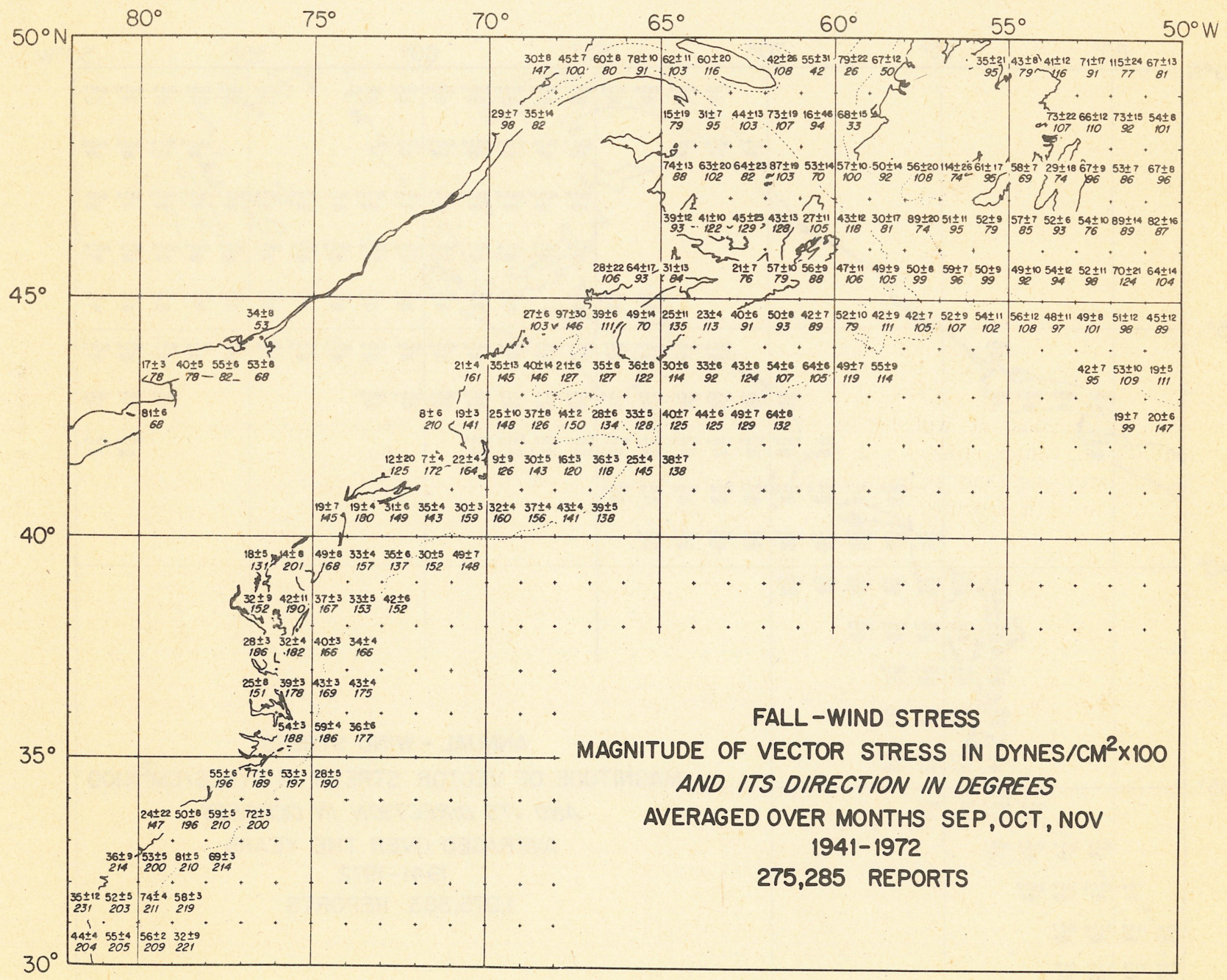

FIG. 12. As in Fig. 8 except for fall. 


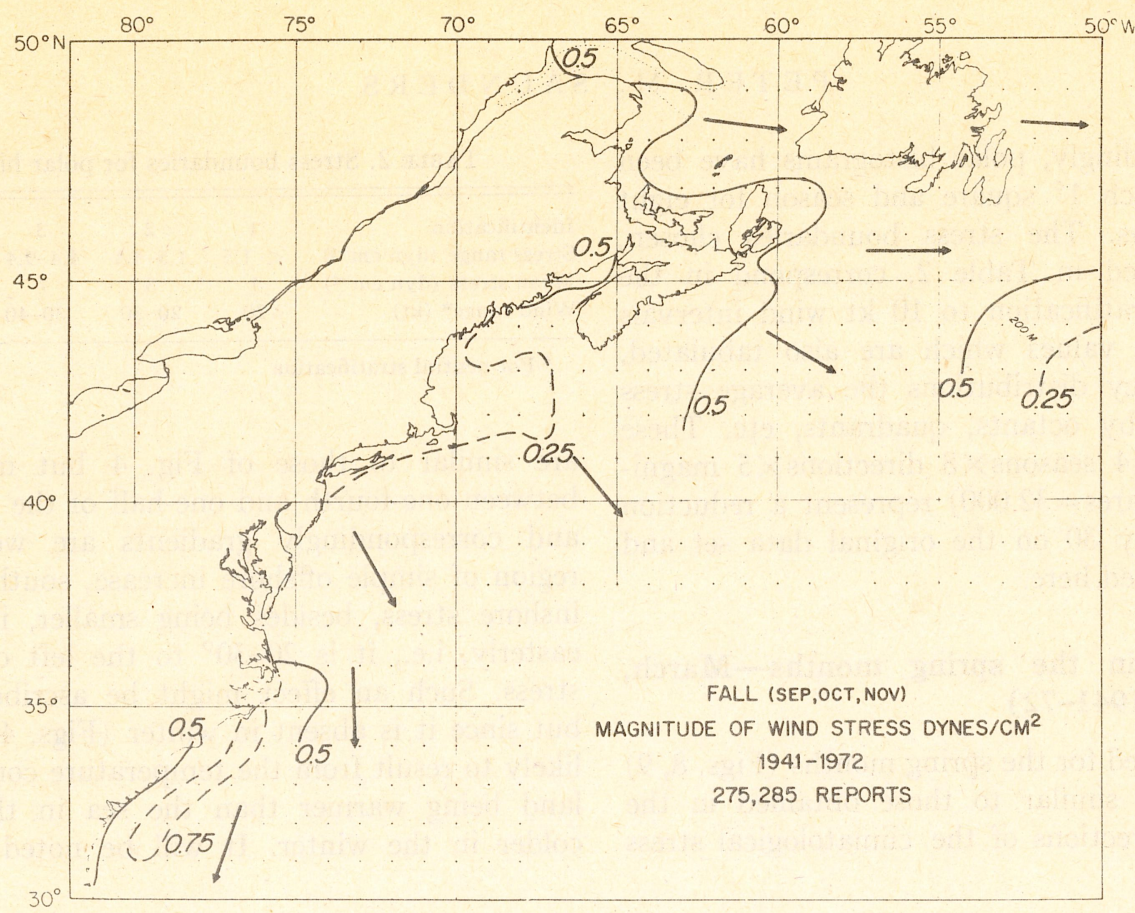

Fig. 13. Contours of magnitude from Fig. 12.

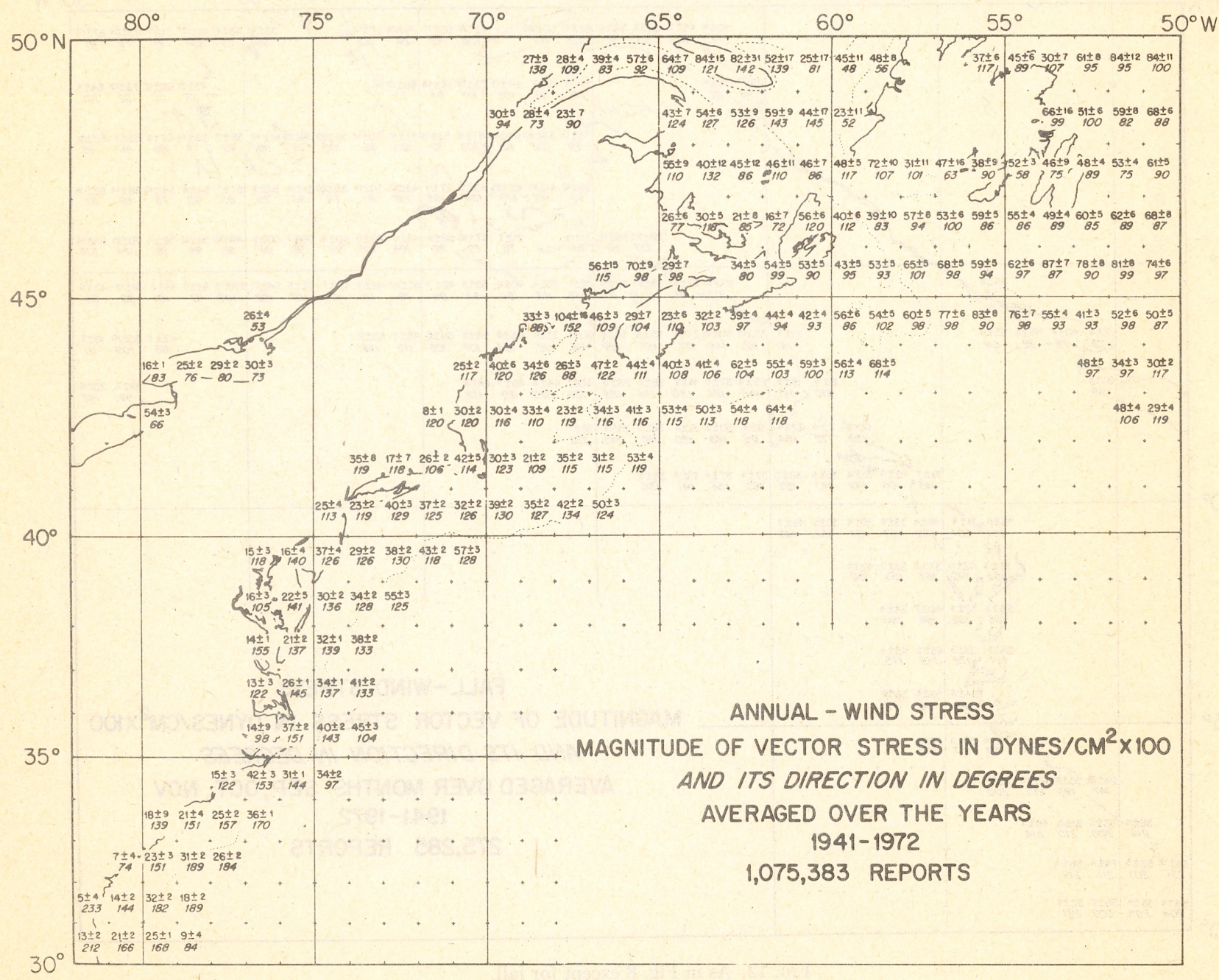

FIG. 14. As in Fig. 8 except annual climatological wind stress. 


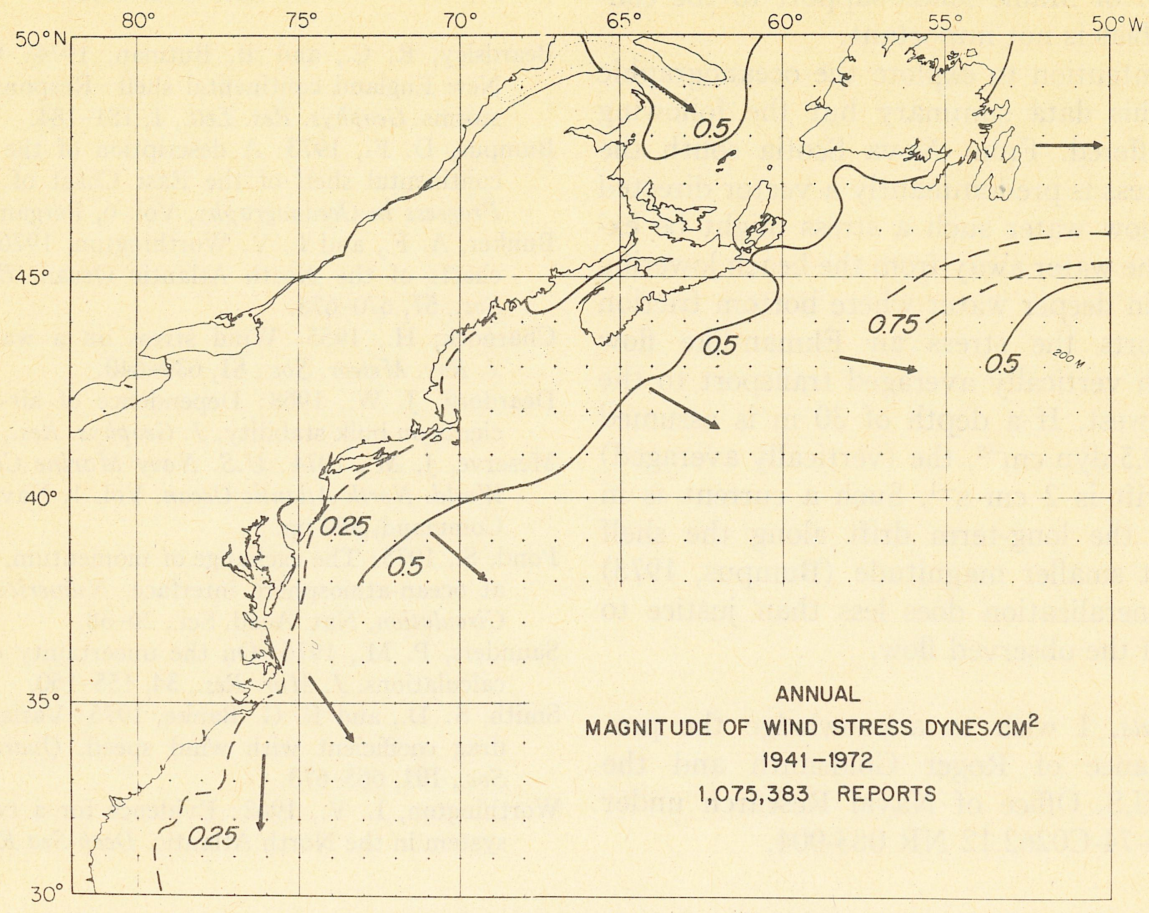

FIG. 15. Contours of magnitude from Fig. 14.

directions are very similar for these two seasons, as are the total number of observations.

\section{Wind stress in the summer months-June, July, August (1941-72)}

The results derived for the summer month (Figs. $10,11)$ are quite different from those of the three other seasons of the year. The direction of the climatological stress is everywhere north and east rather than south and east. Magnitudes are lower, reaching values of $0.3-0.4$ dyn $\mathrm{cm}^{-2}$ in the region south of Newfoundland and quite generally being only $0.1-0.2$ dyn $\mathrm{cm}^{-2}$. Offshore gradients are very weak. It was anticipated that a nearshore intensification, resulting from sea breezes, might be found. Since the times of reporting are 0700 and 1900 locally its absence must rather be expected. This is believed to be the only evidence for bias in the data, a topic returned to in Section 8.

\section{Wind stress in the fall months-September, October, November (1941-72)}

In the fall months while the climatological stress remains small almost everywhere its direction reverts to that of the winter and spring (Figs. 12, 13). A remarkable exception is the region from northern Florida to Cape Hatteras where the stress is toward the south-southwest and shows a narrow stress maximum
$100 \mathrm{~km}$ off the coast. We know of no explanation of this regional peculiarity which is seen in monthly detail in Fig. 3c. Again a minimum in the stress magnitude occurs southeast of the Grand Banks and a weak maximum in the northern Gulf of Maine (as is also found in winter and spring).

\section{Annual average of wind stress (1941-72)}

Figs. 14 and 15 show the annual average data and a contoured magnitude map, respectively. Because of the strength of the winter pattern and the similarity of the fall and spring maps it closely resembles all three seasons, showing little influence of the summer pattern. The results are quite similar to those of Bunker and Worthington (1976). The total number of observations (just over one million) is equally distributed among the four seasons so that no bias should be apparent. When this investigation was begun concern was expressed that bias might appear because a storm avoidance procedures. Ships returning to port have no option but to encounter and report storms. Ships leaving port might delay until the worst of a storm was passed before venturing out, but this would artificially lower both the nearshore and offshore frequency of strong winds (since the storm would generally outrun ships) and would also lower the mean. So far no practicable way has been found of evaluating this suggestion, but the nearshore maxi- 
mum in the Gulf of Maine lends support to the conjecture that the bias is not important.

It is not our intention to explore the oceanographic significance of this data summary but the following comments are offered. From Nova Scotia south the climatological stress is predominantly a vector directed offshore. In shallow water such a stress might be expected to drive the water away from the beach lowering mean sea level: in deeper water where bottom friction no longer supports the stress an Ekman-like flow might result with vertically averaged transport to the south and southwest. If a depth of $30 \mathrm{~m}$ is assumed with a stress of $0.5 \mathrm{dyn} \mathrm{cm}^{-2}$, the (vertically averaged) wind induced drift is $2 \mathrm{~cm} \mathrm{~s}^{-1}$. Such a current is in the direction of the long-term drift along the shelf but of somewhat smaller magnitude (Bumpus, 1973) although this generalization does less than justice to the complexity of the observed flow.

Acknowledgments. I wish to acknowledge the programming assistance of Roger Goldsmith and the support of the U.S. Office of Naval Research under Contract N00014-74-C0262.12 NR 083-004.

\section{REFERENCES}

Beardsley, R. C., and B. Butman, 1974: Circulation on the New England continental shelf: Response to strong winter storms. Geophys. Res. Lett., 1, 181-184.

Bumpus, D. F., 1973: A description of the circulation on the continental shelf of the East Coast of the United States. Progress in Oceanography, Vol. 6, Pergamon Press, 111-157.

Bunker, A. F., and L. V. Worthington, 1976: Energy exchange charts of the North Atlantic Ocean. Bull. Amer. Meteor. Soc., 57, 670-678.

Charnock, H., 1955: Wind stress on a water surface. Quart. J. Roy. Meteor. Soc., 81, 639-640.

Deardorff, J. W., 1968: Dependence of air-sea transfer coefficients on bulk stability. J. Geophys. Res., 73, 2549-2557.

Meserve, J. M., 1974: U.S. Navy Marine Climatic Atlas of the World. North Atlantic Ocean. Vol. 1, Naval Weather Service Command, $369 \mathrm{pp}$.

Pond, S., 1975: The exchange of momentum, heat and moisture at ocean-atmosphere interface. Numerical Models of Ocean Circulation, Nat. Acad. Sci., 26-38.

Saunders, P. M., 1976: On the uncertainty of wind stress curl calculations. J. Mar. Res., 34, 155-160.

Smith, S. D., and E. G. Banke, 1975: Variation of sea surface drag coefficient with wind speed. Quart. J. Roy. Meteor. Soc., 101, 665-673.

Worthington, L. V., 1962: Evidence for a two-gyre circulation system in the North Atlantic. Deep-Sea Res., 9, 51-67. 


\section{MANDATORY DISTRIBUTION LIST}

FOR UNCLASSIFIED TECHNICAL REPORTS, REPRINTS, \& FINAL REPORTS PUBLISHED BY OCEANOGRAPHIC CONTRACTORS

OF THE OCEAN SCIENCE AND TECHNOLOGY DIVISION

OF THE OFFICE OF NAVAL RESEARCH

\section{(REVISED FEBRUARY 1978)}

1 Director of Defense Research and Engineering

Office of the Secretary of Defense Washington, D.C. 20301

ATTN: Office Assistant Director (Research)

Office of Naval Research Arlington, VA 22217

1 ATTN: (Code 460)

1 ATTN: (Code 102-OS)

1 ATTN: (Code 200)

1 CDR J.C. Harlett, (USN) ONR Representative Woods Hole Oceanographic Inst. Woods Hole, MA 02543

1 Office of Naval Research Branch office 495 Summer Street Boston, MA 02210

Director Naval Research Laboratory Washington, D.C. 20375

6 ATTN: Library, Code 2620
1 National Oceanographic Data Center

National Oceanic \& Atmospheric Administration $330 \mathrm{C}$ Whitehaven St., N.W. Washington, D.C. 20235

12 Defense Documentation Center

Cameron Station

Alexandria, VA 22314

Commander

Naval Oceanographic Office Washington, D.C. 20373

1 ATTN: Code 1640

1 ATTN: Code 70

3 NORDA 430 NSTL Station, MS 39529

2 CO NORDA NSTL Station, MS 39529 



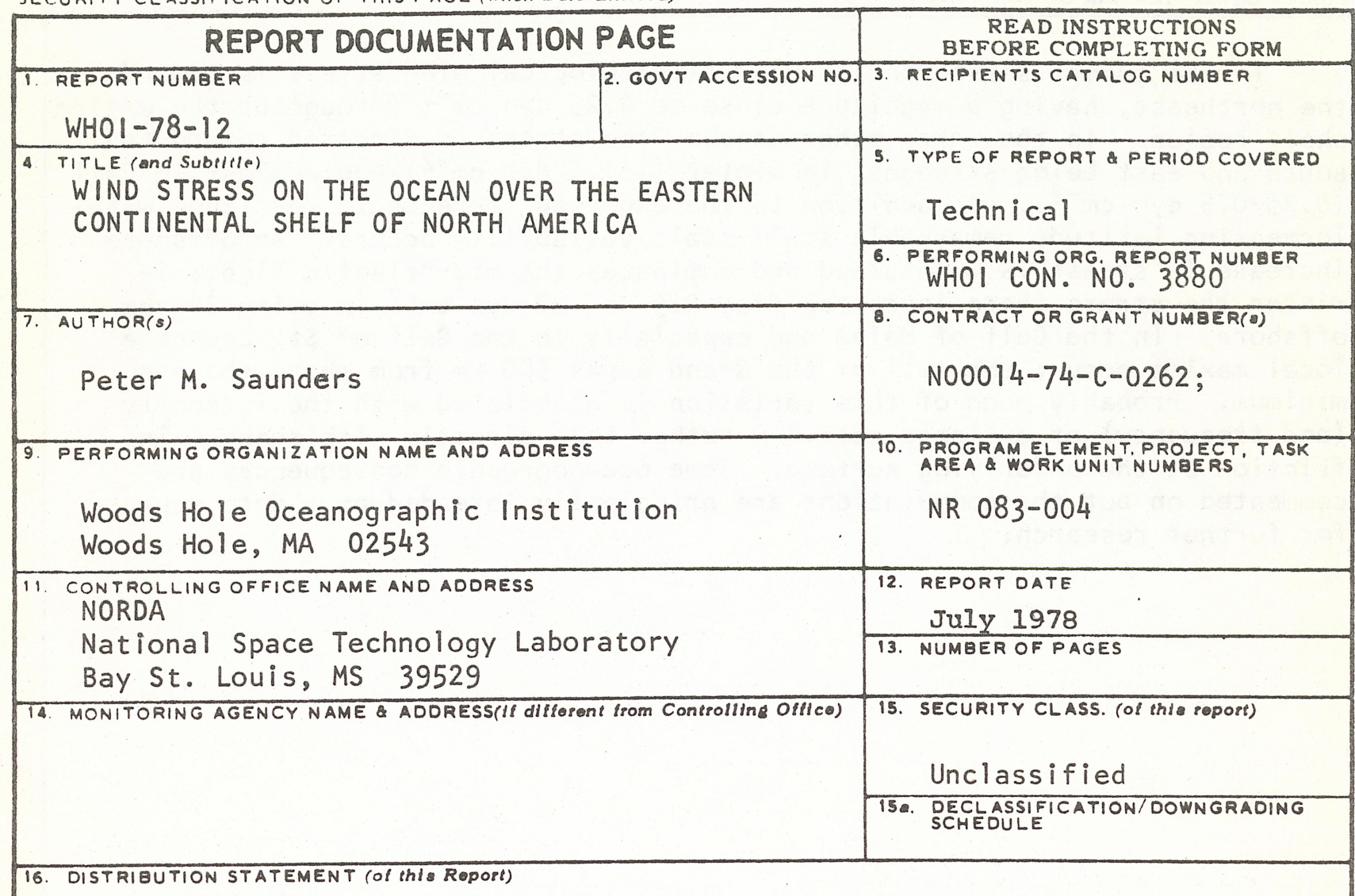

Approved for public release; distribution unlimited.

17. DISTRIBUTION STATEMENT (of the abstract entesed in Block 20, If difforent from Roport)

18. SUPPLEMENTARY NOTES

Reprinted from the "Journal of Physical Oceanography, Vol. 7, No. 4, July 1977, pp. 555-566".

19. KEY WORDS (Continue on peverse alde If neceseary and identlfy by block number)

1. Wind Stress

2. American Continental Shelf Waters (Atlantic)

3. Drag Coefficient

20. ABSTRACT (Continue on poverse oide if necoseary and ldontlly by block number)

Employing one million ship reports gathered in the years 1941-72 seasonal averages of the wind stress and its standard deviation have been computed for the shelf region of the eastern North American continent (out to a depth of $200 \mathrm{~m}$ ). A drag coefficient is assumed which increases with wind speed, from $1.0 \times 10^{-3}$ at $5 \mathrm{~m} \mathrm{~s}^{-1}$ to $2.3 \times 10^{-3}$ at $25 \mathrm{~m} \mathrm{~s}^{-1}$. Atmospheric stratification is taken into account but its effect is shown to be small.

(Cont. on back) 
In the summer season the 32-year climatological wind stress is toward the northeast, having a magnitude close to 0.25 dyn $\mathrm{cm}^{-2}$ throughout the entire shelf region. In the three other seasons the stress is directed toward the south and east being strongest in winter $\left(1-1.5 \mathrm{dyn} \mathrm{cm}^{-2}\right)$ and weakest in fall (0.25-0.5 dyn $\left.\mathrm{cm}^{-2}\right)$. In addition to the expected increase in magnitude with increasing latitude remarkable small-scale variability occurs. An offshore increase in stress is widespread and dominates the mid-Atlantic Bight; in winter the stress there increases from 0.5 to 1.0 dyn $\mathrm{cm}^{-2}$ in going $200 \mathrm{~km}$ offshore. In the Guif of Maine and especially in the Gulf of St. Lawrence local maxima occur; the tail of the Grand Banks $500 \mathrm{~km}$ from shore shows a minimum. Probably much of this variation is associated with the intensity (and frequency) of cyclonic activity rather than directly with changes in friction at the underlying surface. Some oceanographic consequences are. commented on but the computations are principally intended as a data source for further research. 


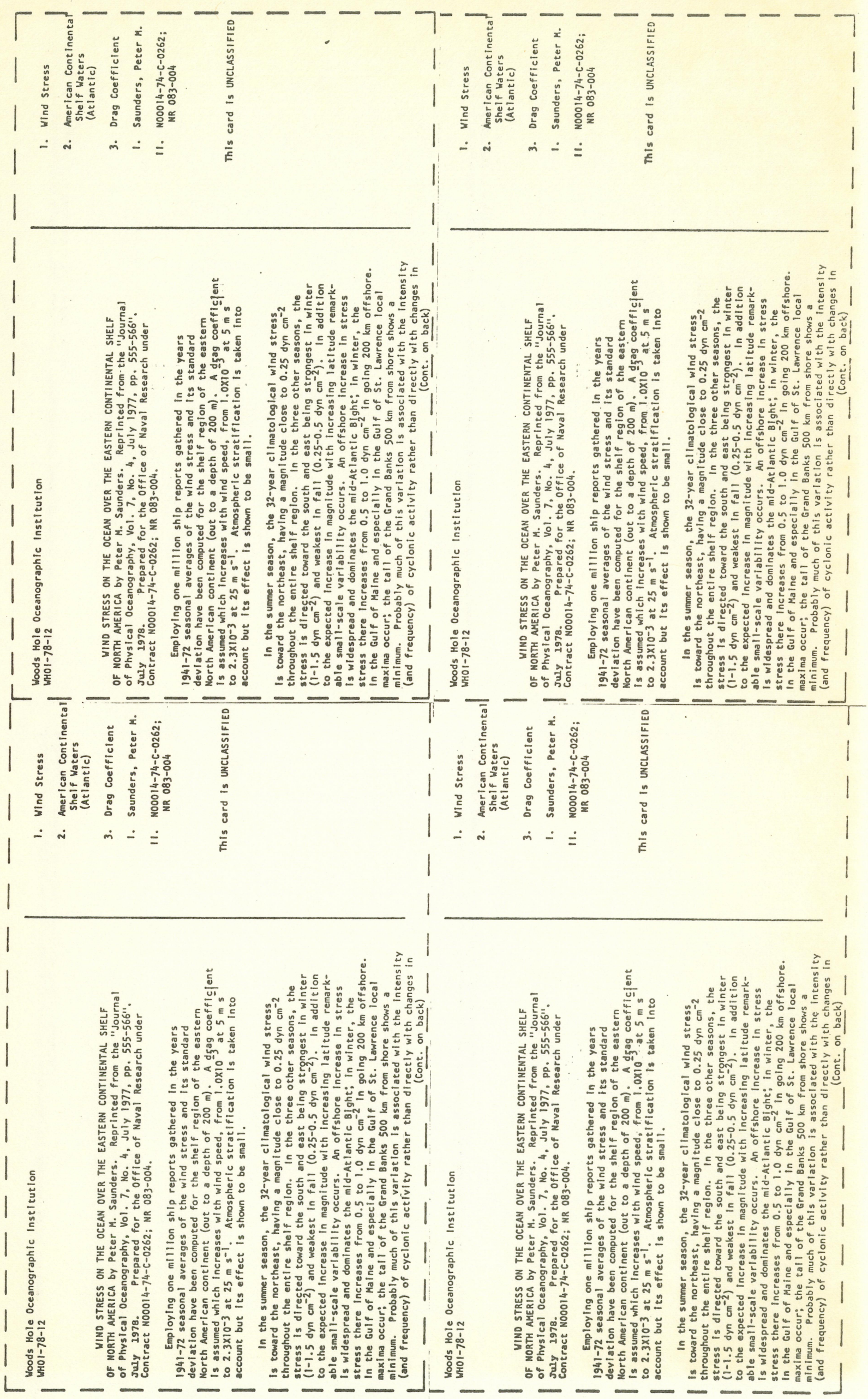



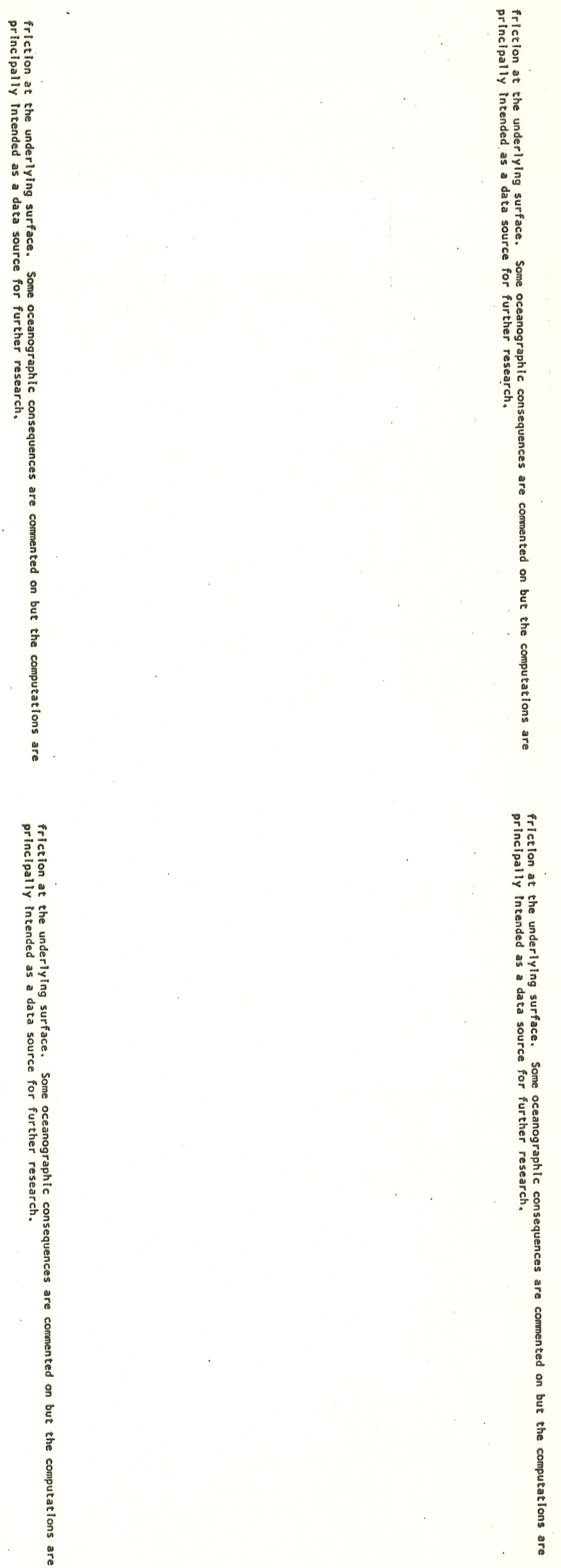